\title{
Depicting favorite organizational culture: An empirical case study
}

\author{
Habibollah Ranaei kordshouli ${ }^{a^{*}}$, Ebadallah Baneshi $^{\mathrm{b}}$ and Behnam Rezaei
}

${ }^{a}$ Assistant professor, Department of Economics \& Social Sciences, Shiraz University, Shiraz, Iran

${ }^{b}$ Assistant professor, Department of Human Sciences, Hormozgan University, Hormozgan, Iran

${ }^{c}$ Master of Business Management, Department of Accounting \& Management, Allameh Tabataba'i University, Tehran, Iran

\section{H R O N I C L E A B S T RA C T}

Article history:

Received June 22, 2013

Received in revised format 28 August 2013

Accepted 21 September 2013

Available online

September 242013

Keywords:

Organizational culture

Mapna Company

Favorite organizational culture

Traits

Indexes

Competing Values Framework

\begin{abstract}
The purpose of this study is to develop a model to depict favorite organizational culture. The research population consists of all Mapna's executive managers and the research sample includes 19 managers. In order to depict favorite organizational culture, in the first step, three approaches are applied and then the results of these three approaches are compared. In the first approach, Cameron and Quinn (1999) framework [Cameron, K. S., \& Quinn, R. E. (2011). Diagnosing and changing organizational culture: Based on the competing values framework. John Wiley \& Sons] and success indexes are used to determine favorite organizational culture. In the second approach, benchmarking technique is applied by implementing the Denison organizational culture database. In the third approach, based on competitive value framework (CVF), a questionnaire is developed and distributed among managers and the result is applied to depict favorite organizational culture. In order to analyze data, descriptive statistics are applied and the results indicate that all of these three approaches maintain the same results. Regarding to these approaches, one or all of these approaches are applicable for depicting favorite culture. Finally, the rate of gap between status quo and favorite organizational culture can be assessed and we can develop and implement plans for improving organizational culture.
\end{abstract}

\section{Introduction}

Many researchers have studied organizational culture as a source of competitive advantage and considered it as a key factor to success for contemporary organizations. In studies, there are a lot of definitions for organizational culture (e.g. Pascal \& Athos, 1981; Deal \& Kennedy, 1982; French \& Bell, 1984; Schein, 1988; Mobley, et al., 2005) and they have different views about organizational culture such as dominant value supported by organization, the way things accomplished in

*Corresponding author

E-mail address: h.ranaei@gmail.com (H. Ranaei kordshouli) 
organization, base assumptions and credo among organization members and a set of values, beliefs, common perceptions and behavioral norms among organization's members. Denison (1996) believes every organization has its own method for performing jobs and this way influences all organizational lifecycle. Thus, organizational culture can be defined as values, beliefs, principles observed as a framework for systems and managerial activities. One of the essential factors on reaching success within organizations is to learn more about organizational culture, to direct and to improve it towards favorite organizational culture. In this research, depicting favorite organizational culture has been extensively studied and three existing approaches are investigated as follows,

In the first approach, Cameron and Quinn's approach was implemented and within their methodology framework, favorite organizational indexes were extracted and they were ranked (Cameron \& Quinn, 2011). The second approach is associated with benchmarking technique and Denison organizational database data has been implemented. Finally, in the third approach, by using organizational culture diagnosing model based on competitive value framework (CVF) developed using Denison model.

\section{Materials and Methods}

\subsection{Literature Review}

Studying organizational culture goes back to 1920s (Trice et al., 1993) but many studies do not have a comprehensive and integrated theoretical basis and many important factors in organizational studies have not been included. However, published studies have increased the importance of research in organizational culture. However, the first systematic attempt to understand organizational performance from the perspective of culture was initiated in the 1920s by the Hawthorne studies. These findings emphasize the importance of teamwork culture and norms direct influence on productivity and attitudes (Schuster, 1986). Besides, McGregor (1960) for the first time recommended different forms for evaluating organizational culture studies based on the Hawthorne studies. A large number of scientists also provided integrated framework for the study of organizational culture (Allaire \& Firsirotu 1984; Hatch, 1993; Martin, 1992; Schein, 1985, 1990) but on a general theory of organizational culture, there is little agreement among them. Since culture is a complex phenomenon in which a range of hidden beliefs and assumptions to obvious structures and activities has been spread, some researchers have questioned whether cultures are practically measureable and comparable (Dennison, 1996; Hatch, 1993; Martin, 1992; Schein 1992).

Peters and Waterman (1982) demonstrated that excellent and superior organizations could have strong and positive culture, because this trait of culture cause higher levels of employee involvement and agreement on strategic points and increasing commitment to organization and alignment between employee goals and organizational goals and this is most important factor for increasing productivity and effectiveness. Ouchi (1981) discovered a similar relationship among organizational cultures and increasing productivity (27) and Gregory et al. (2009) concluded that employee's attitude was as a mediator variable in relationship between culture and effectiveness of the organization. Deal and Kennedy (1982) noted the importance of a strong culture and performance. Also, Kotter and Heskett (1992), Smerek and Denison (2007) and Denison et al. (2007) demonstrated that culture had strong and dramatic effect on organization performance, including economic performance. A significant number of organizational culture models are based on a known framework as competing values framework. These frameworks consist of four trait of culture and focusing on each one will lead to certain outcomes. In this section, models used for depicting favorite culture are discussed (Ranaei, 2009; Ranaei \& Ghaffarnia, 2009; Ranaei \& Ghorbani, 2007).

\section{A. Cameron and Quinn Model of Diagnosing Organizational Culture}

Cameron and Quinn (1999) offered specific methods for understanding and changing organizational culture based on the competitive values framework originally proposed by Quinn and Rohrbaugh (1983). The evolutionary nature of this model has been investigated in several studies. This model 
has a typological approach to make a distinction between different traits of organizational culture. Therefore, corresponding four models in the context of competitive values framework, here are four definitions for organizational culture (Cameron \& Quinn, 1999) as follows,

1. Clan culture(Ethnic): based on the internal coherence and enhancing employee morale

2. Adhocracy culture: the centrality of dynamism, flexibility, entrepreneurship and innovation

3. Market-based culture: the centrality of competition, efficiency and productivity

4. Hierarchical culture (conservative) focusing on stability and maintaining the existing situation.

In this model development process, based on the results of studies conducted by different researchers, there have been efforts to introduce a different approach to understand the organizational culture while using different typology to provide a model for evaluating and measuring cultural congruence and elements within the organization. Based on this pattern, if all reviewed characteristics are in a single quadrant of the CVF axis, there is a proportion and compatibility within the elements of the existing culture of an organization. Regarding above goals, Cameron and Freeman reviewed the studies in this field and tried to introduce a set of key characteristics that define each culture (Cameron \& Freeman, 1991): 1) Dominant Attributes 2) Leader style 3) Organization glue 4) Strategic Emphases. In future studies the number of these variables increased and two were added, that is management of employee and criteria of success. Thus, regarding six mentioned criteria, we can distinguish various organizational cultures shown in Fig 1 (Cameron \& Quinn, 1999).

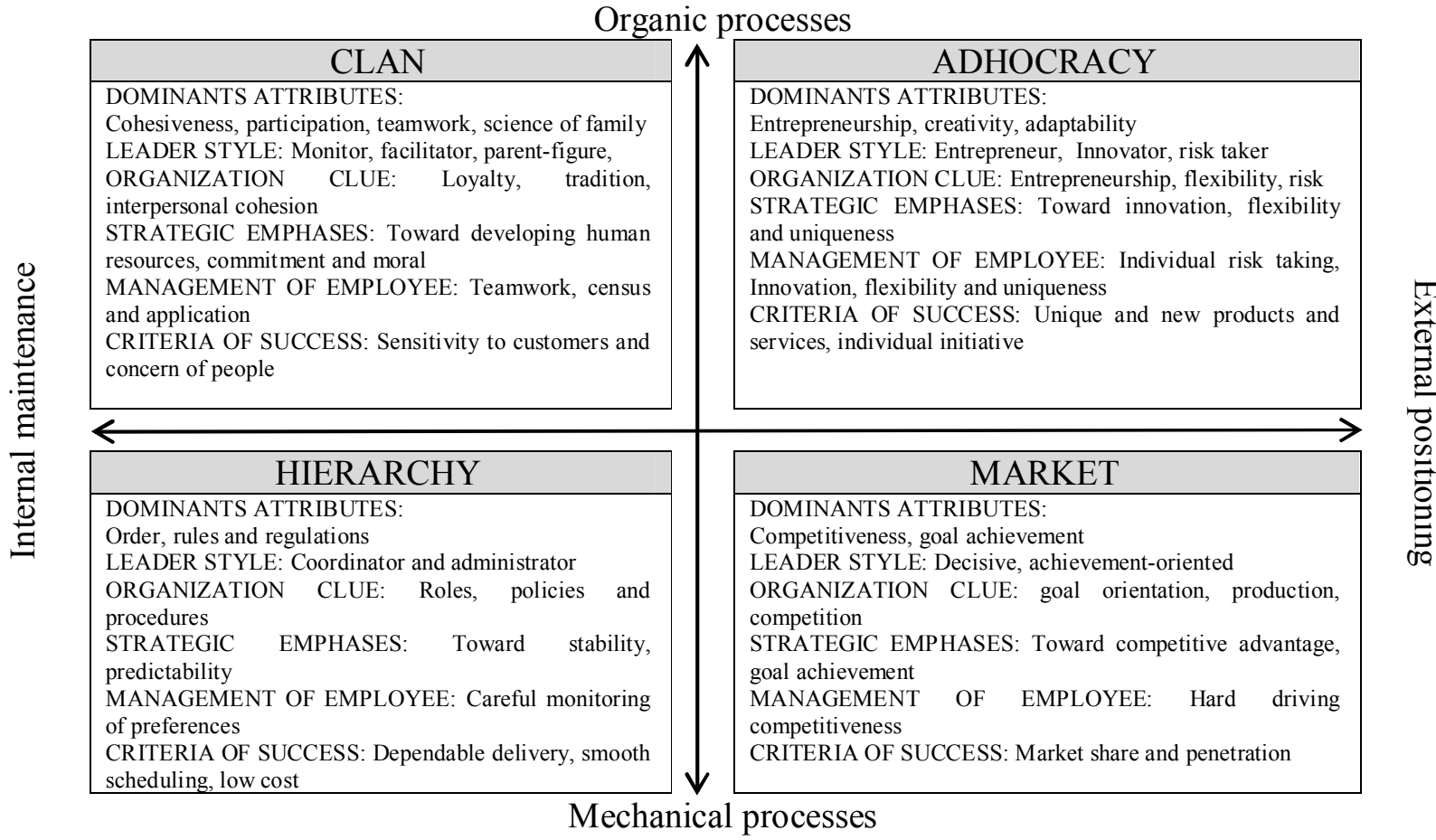

Fig. 1. Different Characteristics of Cultures (Cameron \& Quinn, 1999)

In this model, the culture relevance and homogeneity comes out when values or dominant attributes of organization, leader style, and organization glue, strategic emphases, employee management styles and also "Criteria of success" are compatible and congruent and shows a trait of culture.

\section{B. Denison Model of Diagnosing Organizational Culture}

Denison model consists of four main trait of organizational culture including involvement, adaptability, consistency and mission (Denison \& Fisher 2005; Denison \& Mishra 1995, 1998; Schmidt \& Jackson, 2005). 
These four traits are expressed in terms of management practices. Management practices comprise of clarified performances associated with four organizational culture traits and they are derived from dominant beliefs, values and assumptions and fortified by them in the organization. These management practices are measured by 12 indexes that comprise the model (Mobley et al., 2005, Denison et al., 2005 , 2000). On the other hand, each of these traits is measured by three management practices indexes and each of these indexes is measured by five questions, finally for measuring all indexes, a 60 case questionnaire is used. After measuring all the traits and indexes and putting them in each model, the resulting is called "organizational scheme" (Ghorbani et al., 2009; Monavarian et al., 1999). In Fig. 2, Denison organizational culture is shown.

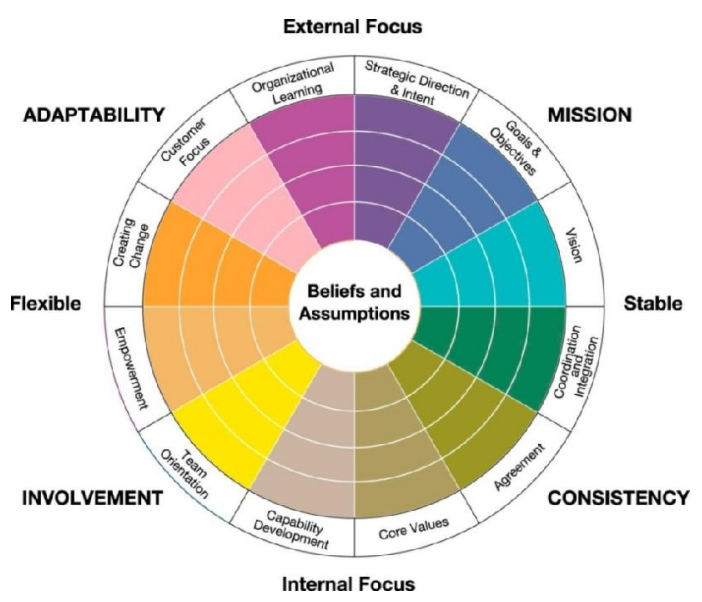

Fig. 2. Denison Model of Diagnosing Organizational Culture

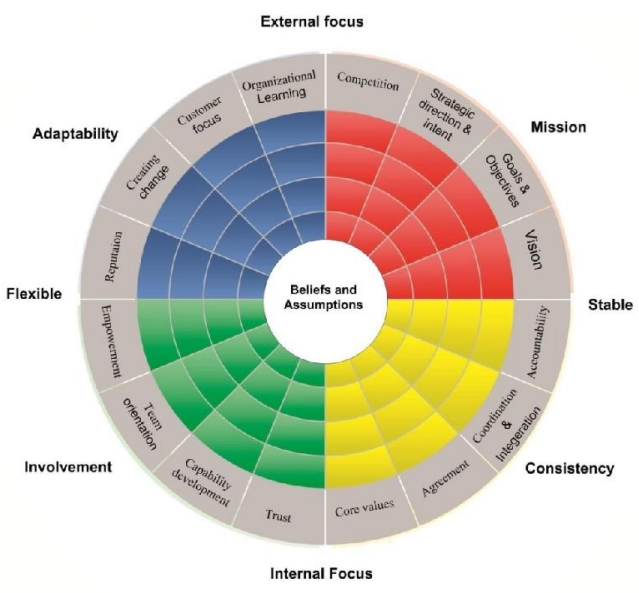

Fig. 3. Mapna's Model of Diagnosing Organizational Culture

\section{Mapna Model of Diagnosing Organizational Culture}

In Mapna, Denison model has been chosen as a basis and it has been developed. To localize and to adapt to company's values, a procedure has been defined and it has been implemented. Several sessions held with top manager. An index added to each Denison organizational culture traits i.e. (Reputation, trust, accountability and competition) has been added to 12 indexes in the model. Therefore, Mapna's model of diagnosing organizational culture has 4 traits and 16 indexes and a questionnaire with 80 questions measured status quo of Mapna's organizational culture.

\subsection{Methodology}

The research is applicable, utilizing a descriptive- comparative survey method that has depicted Mapna Company's favorite organizational culture.

\subsubsection{Statistical Population and Samples}

Regarding this survey goals, population and samples number are equal to 19 and comprise all Mapna and its subsidiaries top managers. The average age, work experiences in Mapna and in total of participants were 52.4, 9.1 and 29.3 years. In addition, $47.4 \%$ of the participants hold bachelor degree of science and $52.6 \%$ of them hold master degree.

\subsubsection{Data Collection Tools}

In this study, 3 approaches have been used for data collection. First, using Quinn success indexes, a questionnaire suggested that collected 24 success indexes from the viewpoint of top managers. In this approach, regarding company's successful performances, from the viewpoint of managers, related favorite culture and priorities were depicted. The mangers were asked to rank the indexes regarding A) perspective, goals and future strategies B) Status quo and strength and weaknesses. C) Company 
experiences. This questionnaire includes 6 questions where each contains 4 success indexes associated with a specific trait of culture. Respondents were asked to assess each index. In the second approach, Denison organizational culture database and benchmarking technique has been used to depict favorite culture. For benchmarking Eightieth percentile of Denison database has been considered as criteria for favorite culture. On the other hand, favorite culture is to get to a point upper than $80 \%$ of companies in the database. In the third approach, Denison model as a base, used with a localized model. Four more indexes were added to Denison model provided from recent researches and models. A questionnaire with 80 questions provided based on Likert spectrum, then using questionnaire, Mapna's mangers were requested to depict 16 indexes regarding status quo, future perspective in a five year horizon.

\subsubsection{Data Analysis}

To analysis, classify and to get results, descriptive statistics such as frequency, relative frequency, mean, standard deviation, tables, charts, etc. have been used. All statistical operations were carried out using Excel and SPSS software.

\section{Findings}

\section{First Approach: Depicting Mapna's Favorite Organizational Culture Using Quinn Success Indexes}

As shown in Table 1 to assess each trait, every 6 success indexes was classified to a trait of culture. Thus, average score of each trait was calculated to measure success. Results showed that in Mapna company's higher score is for involvement, then adaptability, mission and consistency.

Table 1

Average Score of Success Indexes of 4 Culture Traits

\begin{tabular}{|c|c|c|c|c|c|}
\hline Items & Indexes & $\begin{array}{l}\text { Scores } \\
(1-76)\end{array}$ & Trait & $\begin{array}{c}\text { Average } \\
\text { Score }(1-76)\end{array}$ & $\begin{array}{c}\text { Average } \\
\text { Score (From 100) }\end{array}$ \\
\hline 1 & Empowerment \& Capability development & 65 & \multirow{6}{*}{ Involvement } & \multirow{6}{*}{54.5} & \multirow{6}{*}{71.7} \\
\hline 2 & Team work \& development & 59 & & & \\
\hline 3 & Morale Improvement & 58 & & & \\
\hline 4 & Experts Absorption & 57 & & & \\
\hline 5 & Developing employee participations & 55 & & & \\
\hline 6 & Reducing Complaints & 33 & & & \\
\hline 7 & Product diversification & 61 & \multirow{6}{*}{ Adaptability } & \multirow{6}{*}{52.5} & \multirow{6}{*}{69.1} \\
\hline 8 & New Resources & 56 & & & \\
\hline 9 & Customer focus and satisfaction & 55 & & & \\
\hline 10 & Creativity and new products & 53 & & & \\
\hline 11 & More creativity More return & 50 & & & \\
\hline 12 & Increasing $\mathrm{R} \& \mathrm{D}$ & 40 & & & \\
\hline 13 & Increasing productivity & 62 & \multirow{6}{*}{ Mission } & \multirow{6}{*}{44.2} & \multirow{6}{*}{58.2} \\
\hline 14 & Company's rank promotion in industry & 48 & & & \\
\hline 15 & Liquidity and funds & 45 & & & \\
\hline 16 & Increasing profitability & 41 & & & \\
\hline 17 & Increasing stock price & 37 & & & \\
\hline 18 & Decreasing new product/service introduction time & 32 & & & \\
\hline 19 & Products/Service Quality improvement & 51 & \multirow{6}{*}{ Consistency } & \multirow{6}{*}{38.3} & \multirow{6}{*}{50.4} \\
\hline 20 & On time delivery of orders/plans/projects & 48 & & & \\
\hline 21 & Decreasing defected products/Services & 37 & & & \\
\hline 22 & Decreasing regulation violations (Errors) & 34 & & & \\
\hline 23 & Increasing savings and costs reduction & 31 & & & \\
\hline 24 & Decreasing wasting. & 29 & & & \\
\hline
\end{tabular}

In Fig. 4, the average score of culture trait and its indexes in favorite status is compared. As seen, there are differences between status quo (Red, Blue, Green and Yellow colors) and average scores of favorite organizational culture. Higher gap are for adaptability and involvement. 


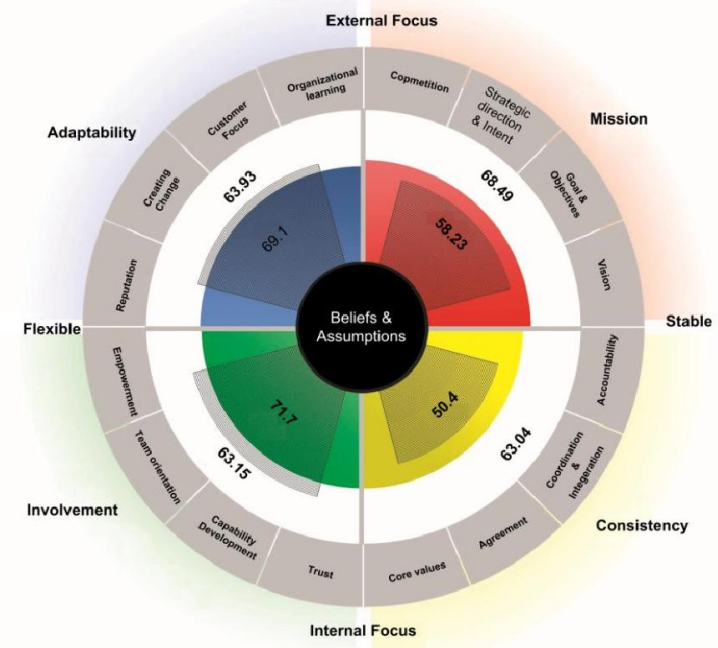

Fig. 4. Comparing Status Quo Trait Scores with Favorite Organizational Culture Using Success Indexes

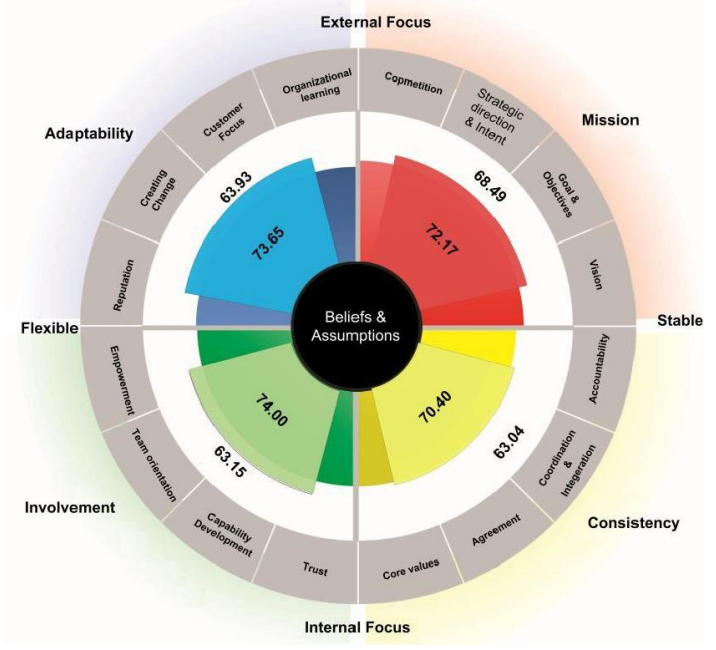

Fig. 5. Comparing Status Quo Trait Scores with Favorite Organizational Culture Using Benchmarking Technique

\section{Second Approach: Depicting Mapna's Favorite Organizational Culture Using Benchmarking} Technique

As mentioned before, for using this technique the eightieth percentile of score of the Denison database is used and this status (scores) is considered as favorite culture. Fig. 5 compares status quo (Red, Blue, green and yellow colors) and favorite culture using this technique. Again as seen higher gap is for involvement and adaptability, then consistency and mission. Regarding relative priority and the gap between status quo and favorite status, company first have to focus on involvement and adaptability.

\section{Third Approach: Depicting Mapna's Favorite Organizational Culture Using Top Manager's Viewpoint}

As mentioned before, managers have been asked to depict favorite status regarding future perspective and to determine 16 indexes effect on success in a 5-year scope and the results are shown in Fig. 6. There are higher gaps between involvement statuses and lower belongs to mission.

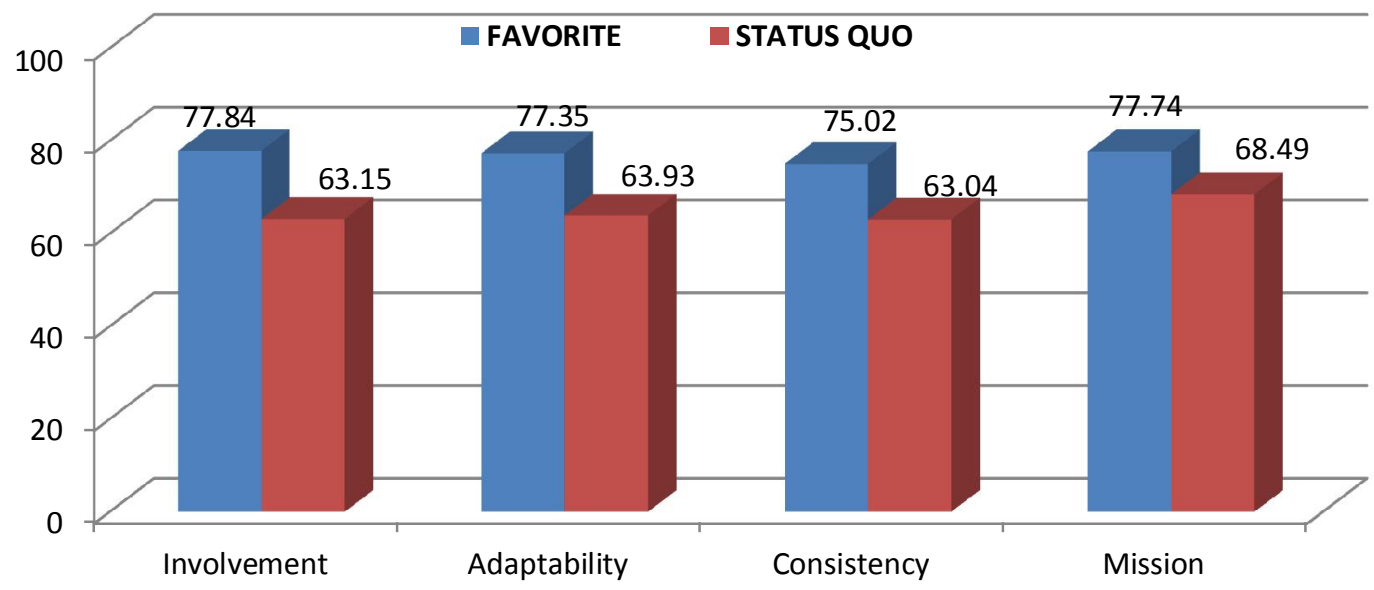

Fig. 6. Comparing Status Quo Trait Scores with Favorite Organizational Culture Using Top Manager's Viewpoint 


\section{Discussion and Conclusions}

The results of this study are consistent with Peters and Waterman (1982), Ouchi (1981) and Gregory et al. (2009) since it looks from different perspective to the case. However, it implicitly shows that excellent and superior of Mapna have strong and positive culture, because these traits of culture cause higher levels of employee involvement and agreement on strategic points and increase commitment to organization and alignment between employee goals and organizational goals. This is the most important factor for increasing productivity and effectiveness.

First approach results showed higher gap belongs to indexes that is for involvement and then adaptability. In second approach top mangers' viewpoint showed that within 4 traits higher gap was for involvement and adaptability. Thus we must pay more attention to these traits. In addition, benchmarking technique showed Mapna averages were lower than $80 \%$ of favorite status (Denison Database). Thus to reach a favorite level, 10.85\% involvement, $9.72 \%$ Adaptability, $7.36 \%$ consistency and $3.68 \%$ mission traits must be improved. Third approach result is aligned with two other approaches. Involvement is in first place and then adaptability.

In Table 2, each trait in each approach is ranked by the gap between status quo and favorite status. Only difference is that in first approach mission is in the third place while in second and the third approaches mission was in last place.

Table 3

Comparing 3 approaches result

\begin{tabular}{llll}
\hline & \multicolumn{3}{c}{ Approaches } \\
\cline { 2 - 4 } Priority & Success indexes & Benchmarking Technique & Top managers Viewpoint \\
\hline 1 & Involvement & Involvement & Involvement \\
2 & Adaptability & Adaptability & Adaptability \\
3 & Mission & Consistency & Consistency \\
4 & Consistency & Mission & Mission \\
\hline
\end{tabular}

Regarding results congruence, each approach can be used as favorite organizational culture and hence improvement plans must be provided and implemented. Since using these approaches is time consuming and costly, we suggest companies, regarding their situations choose approach. For example, an international company is suggested to use benchmarking and comparing itself with international companies.

\section{Research Limitation and Future Suggestions}

It is suggested to researchers to know the company type as a governmental one; there were some problems in data collection and holding sessions with the managers. In addition, localizing Denison model requires considering local people cultures and interests and we need for a modified model. For further study, it is suggested to focus on priorities of results including further study of involvement and adaptability indexes.

\section{References}

Allaire, Y., \& Firsirotu, M. E. (1984). Theories of organizational culture. Organization studies, 5(3), 193-226.

Cameron, K., \& Freeman, S. (1991). Organizational Culture and Organizational Development: A Competing Values Approach. In Woodman, RW \& Pasmore, WA (Eds.), Research In Organizational Change And Development, JAI Press, London, Pp. 25-38

Cameron, K. S., \& Quinn, R. E. (2011). Diagnosing and changing organizational culture: Based on the competing values framework. John Wiley \& Sons. 
Deal, T. E., \& Kennedy, A. A. (2000). Corporate cultures: The rites and rituals of corporate life. Da Capo Press.

Denison, D. R., Janovics, J., Young, J., \& Cho, H. J. (2006). Diagnosing organizational cultures: Validating a model and method. Documento de trabajo. Denison Consulting Group.

Denison, D. R. (1996). What is the difference between organizational culture and organizational climate? A native's point of view on a decade of paradigm wars. Academy of Management review, 21(3), 619-654.

French, W. L., \& Bell, C. H. (1984). Organization development: Behavioral science interventions for organization improvement (p. 347). Englewood Cliffs, NJ: Prentice-Hall.

Ghorbani M., Asadi H., \& Sharifi M (2009). The relationship of culture and effectiveness in Iranian Sport organization. Journal of sport sciences, 14, 107-118.

Gregory, B. T., Harris, S. G., Armenakis, A. A., \& Shook, C. L. (2009). Organizational culture and effectiveness: A study of values, attitudes, and organizational outcomes. Journal of Business Research, 62(7), 673-679.

Kotter, J. P., \& Heskett, J. L. (1992). Corporate Culture and Performance. Free Press, New York.

Martin, J. (1992). Cultures in Organizations: Three Perspectives. Oxford University Press, New York.

McGregor, D. (1960). The Human Side of Enterprise. New York: McGraw- Hill.

Mobley, W. H., Wang, L., \& Fang, K., (2005). Organizational Culture: Measuring and Developing It in Your Organization. Published in the Harvard Business Review China (March 2005); 128-139

Monavarian A., Ghorbani M., \& Sharifi M. (2006). Organizational culture based on Denison model, Shiraz university press, Shiraz

Ouchi. W.G. (1981). Z Theory. Reading, MH: Addison-Wesley.

Pascal, R. T., \& A. G. Athos (1981). The Art of Japanese Management. New York: Simon \& Schuster.

Peters,T.J., \& Waterman, R.H. (1982). In Search of Excellence: Lessons from Americans Best Run Companies. New York: Harper \& Row.

Ranaei, H., \& Ghafarnia, A. (2009). Human Asset Model of Oil Company. Fourth international human resource conference, Tehran.

Ranaei, H. (2007). Organizational culture management: creating a competing values framework. Journal of Management sciences, 6.

Ranaei H. (2009). Organizational culture management: principles approaches and models. Oil Ministry publications, Tehran.

Ranaei, H., \& Ghorani, F. (2007). Competing values framework application in organizational culture surveys. Journal of management culture, 15.

Schein, E. (1985). Organizational Culture and Leadership. Jossey-Bass San Francisco, CA.

Schein, E. (1990). Organizational Culture. Amer. Psychologist 45, 109-119

Schien, E. H. (1988). How culture form, develops and changes. San Francisco, CA: Jossey-Bass.

Schuster, F.E. (1986). The Schuster report: The proven connection between people and profit. New York: published by john Wiley.

Smerek, R. E. \& Denison, D. R. (2007). Social Capital in Organizations: Understanding the Link to Firm Performance. In G. T. Solomon (Ed.), Proceedings of the sixty-sixth annual meeting of the Academy of Management (CD), ISSN 1543-8643.

Trice, H.M \& Beyer, J.M. (1993). Culture of Work Organization. Englewood Cliffs, NJ: PrenticeHall. 